\title{
Effects of Cooling Rates after Hot Rolling on the Planar Anisotropy of Extremely Low Carbon Niobium Cold Rolled Sheets*
}

\author{
By Taisuke AKAMATSU, ,* Tetsu SAKAMOTO,,** Mikio TAUMI** and \\ Kunio WATANABE***
}

\begin{abstract}
Synopsis
The effects of the cooling rates after hot rolling on the planar anisotropy of cold rolled $\mathrm{Nb}$ steel sheets with extremely low $\mathrm{C}(\mathrm{C} \sim 0.004 \%, \mathrm{Nb} \sim$ $0.12 \%$ ) were examined. The specimens were hot rolled to $3.2 \mathrm{~mm}$ and cooled variously, i.e., quenching in water, rapid cooling under water spray, air cooling, or furnace cooling, then cold rolled to $0.8 \mathrm{~mm}$, and annealed at $780^{\circ} \mathrm{C}$ for $5 \mathrm{hr}$.

The direction of earing formed upon conical cup test varied from diagonal to longitudinal-transverse in accordance with the decrease of cooling rate after hot rolling.

To clarify the phenomenon, specimens were left in air for several different periods of time after hot rolling and quenched in water. It was found then that the specimens quenched from $\gamma$ state gave rise to earing in diagonal directions and those quenched from $\alpha$ in longitudinal-transverse directions, and that the annealing texture of the sheets earing diagonally was (554) [22 $\overline{5}]$ and those earing longitudinal-transversely was (111) [ $\overline{1} 10]$ plus (111) [11 $\overline{2}]$.

It was conclued that the difference of earing direction can be attributed to the difference of texture formation which is, in turn, affected by the particle size of $\mathrm{Nb}$ carbonitride precipitated in the hot rolled sheet.
\end{abstract}

\section{Introduction}

The effects of $\mathrm{Nb}$ on the properties of mild steel have in the main been recognized by the hardening effect due to its minute precipitates or solid solution for rendering the steel of a high strength.

However we find interesting data from old literatures. According to an American patent by F. M. Beeket and R. Franks ${ }^{1)}$ of 1941, for example, an $0.10 \% \mathrm{C}, 0.65 \% \mathrm{Nb}$ hot rolled steel shows an yield stength of $15 \mathrm{~kg} / \mathrm{mm}^{2}$, and according to the data of strain aging by C. A. Edwards, D. L. Phillips and H. N. Jones, ${ }^{2)}$ an $0.025 \%$ or less C, $0.36 \% \mathrm{Nb}$ steel does not show any strain aging. W. B. Morrison ${ }^{3)}$ has shown that the strain aging at $100^{\circ} \mathrm{C}$ of an $0.15 \% \mathrm{C}, 0.005 \% \mathrm{~N}$ and $0.10 \% \mathrm{Nb}$ steel decreases considerably in either hot rolled or normalized condition. Judging from these data, we expect that a sheet steel with good deep drawability can be manufactured from a low $\mathrm{C}$ and high $\mathrm{Nb}$ steel.

Many reports have been published concerning good drawability of sheet steels ${ }^{4-15)}$ treated by carbonitride forming elements, and some of them describe the texture of cold rolled and annealed sheets in detail.
For example, R. H. Goodenow and J. F. Held ${ }^{7)}$ reported appearance of 6 ears in a $\mathrm{Ti}$ stabilized steel sheet upon cup testing, concluding its main texture

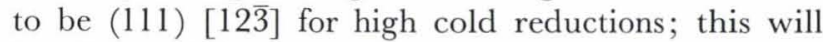
be discussed later with regard to the $\mathrm{Nb}$ stabilized steel sheet.

T. Matsuoka and M. Takahashi ${ }^{8)}$ studied the low $\mathrm{C}, \mathrm{Ti}$ steel and reported the change of annealing textures and of precipitated particle size with soaking temperatures before hot rolling; this also will be discussed with regard to the low $\mathrm{C}$, Nb steel.

O. Akisue and K. Takashina ${ }^{12)}$ studied the rolling and recrystallization textures of low $\mathrm{C}, \mathrm{Nb}$ steel sheets which were hot rolled by hot strip mill of actual works.

In the present investigation, the effects of the hot rolling condition on the earing behaviors of cold rolled and annealed sheets of extremely low C, Nb steel were studied.

\section{Specimens and the Preliminary Experiment about Cooling Rates after Hot Rolling}

\section{Experimental Procedure}

Three steels were melted in a high frequency induction furnace, deoxidized with $\mathrm{Al}, \mathrm{Al}-\mathrm{Si}$, or $\mathrm{Si}$, then cast in air into $100 \mathrm{~kg}$ ingots. The chemical compositions are given in Table 1. These ingots were forged to slabs of $15 \times 90 \times 150 \mathrm{~mm}$ at $1200^{\circ} \mathrm{C}$, soaked at $1300^{\circ} \mathrm{C}$ for $15 \mathrm{~min}$ and hot rolled to a finishing temperature of $900^{\circ}, 850^{\circ}$ or $800^{\circ} \mathrm{C}$ in one pass. A 2-high research hot rolling mill of diameter $200 \mathrm{~mm}$, roll barrel $200 \mathrm{~mm}$, rolling speed $10 \mathrm{~m} / \mathrm{min}$ was used. The finishing temperatures were recorded by a radiation pyrometer appropriately calibrated with $\mathrm{Pt}-\mathrm{Pt} \mathrm{Rh}$ thermocouple. After hot rolling, the specimens were cooled variously, i.e., quenched in water (W.Q.), rapidly cooled under water spray (R.C.), cooled in air (A.C.), and cooled in furnace (F.C); all except W.Q. being slowly cooled in a heat insulating sand bath below $500^{\circ} \mathrm{C}$. The average cooling rates after respective finishing temperatures

Table 1. Chemical compositions of specimens (wt \%)

\begin{tabular}{|c|c|c|c|c|c|c|c|c|c|c|c|c|}
\hline Specimen & $\begin{array}{c}\text { Type of } \\
\text { deoxidation }\end{array}$ & C & $\mathrm{Si}$ & $\mathrm{Mn}$ & $\mathrm{P}$ & $\mathrm{S}$ & Tot. Nb & sol. Nb & sol. $\mathrm{Al}$ & insol. $\mathrm{Al}$ & sol. $\mathrm{N}$ & insol. $\mathrm{N}$ \\
\hline 1 & $\mathrm{Al}$ & 0.0059 & 0.003 & 0.41 & 0.003 & 0.005 & 0.12 & 0.065 & $<0.002$ & 0.003 & 0.0036 & $<0.001$ \\
\hline 3 & $\mathrm{Si}$ & 0.0037 & 0.140 & 0.22 & 0.010 & 0.007 & 0.14 & 0.096 & - & - & 0.0028 & 0.001 \\
\hline
\end{tabular}

* Originally published in Tetsu-to-Hagané, 61 (1975), 80 in Japanese. English version received March $25,1975$.

** Products R \& D Laboratories, Nippon Steel Corp., Fuchinobe, Sagamihara 229.

*** Sakai Iron \& Steel Works, Nippon Steel Corp., Sakai 590. 
are shown in Table 2.

The hot rolled sheets were pickled, cold rolled from 3.2 to $0.8 \mathrm{~mm}$, annealed at $780^{\circ} \mathrm{C}$ for $5 \mathrm{hr}$ at a rate $400^{\circ} \mathrm{C} / \mathrm{hr}$ to $400^{\circ} \mathrm{C}$ then $25^{\circ} \mathrm{C} / \mathrm{hr}$ to $780^{\circ} \mathrm{C}$, and cooled in furnace.

The sheets, both as hot rolled and as cold rolled and annealed (this will be called simply the annealed hereafter), were examined metallographically (optical microscopy, X-ray diffraction for textures) and by hardness, with tensile tests and conical cup tests added for the annealed sheets.

\section{Experimental Results}

The hardness of hot rolled sheets increased with increasing cooling rate. Although the annealed

Table 2. Average cooling rates after hot rolling

\begin{tabular}{l|c|c} 
& $\begin{array}{c}\text { Finishing } \\
\text { temperature }\left({ }^{\circ} \mathrm{C}\right)\end{array}$ & $\begin{array}{c}\text { Average cooling } \\
\text { rate }\left({ }^{\circ} \mathrm{C} / \mathrm{sec}\right)\end{array}$ \\
\hline \multirow{3}{*}{ Rapid cooling } & 900 & 40.2 \\
& 850 & 45.3 \\
& 800 & 53.6 \\
\hline \multirow{2}{*}{ Air cooling } & 900 & 10.3 \\
& 850 & 11.4 \\
Furnace cooling & 800 & 11.1 \\
& 900 & 0.34 \\
& 850 & 0.36 \\
& 800 & 0.40
\end{tabular}

sheets did not show any particular hardness change with cooling rate, the total elongation increased as the cooling rate decreased, whereby an interesting change was observed in the $r$ value and the flange shape of conical cup.

In Fig. 1, planar anisotropy of $r$ value and flange shape of conical cup after cup testing are shown in each quadrant of the circle with respect to the cooling rates. The $r$ values in intermediate directions were calculated on the longitudinal, transverse and diagonal direction values using Hill's method. ${ }^{16)}$

The following facts have become clear with this experiment.

(1) The earing of conical cup changes according to the cooling rates after hot rolling, signifying the change of planar anisotropy in the annealed sheet.

(2) The directions of earing of Specimens 1 and 2 are changed from diagonal to longitudinal-transverse as the cooling rate decreases.

(3) There is no direct correlation between planar anisotropy of $r$ value and flange shape of conical cup.

(4) The flanges having 6 ears (in longitudinal and diagonal directions) are found in Specimen 3. The flange shape and the planar anisotropy of $r$ value do not correspond to each other in this case, as Hill's method fails to apply to complicated cases as will be shown later in Fig. 7.

(5) As is shown in Table 3, specimens finished at $800^{\circ} \mathrm{C}$ show better $\bar{r}$ values but no clear tendency is obtained concerning the cooling rate.
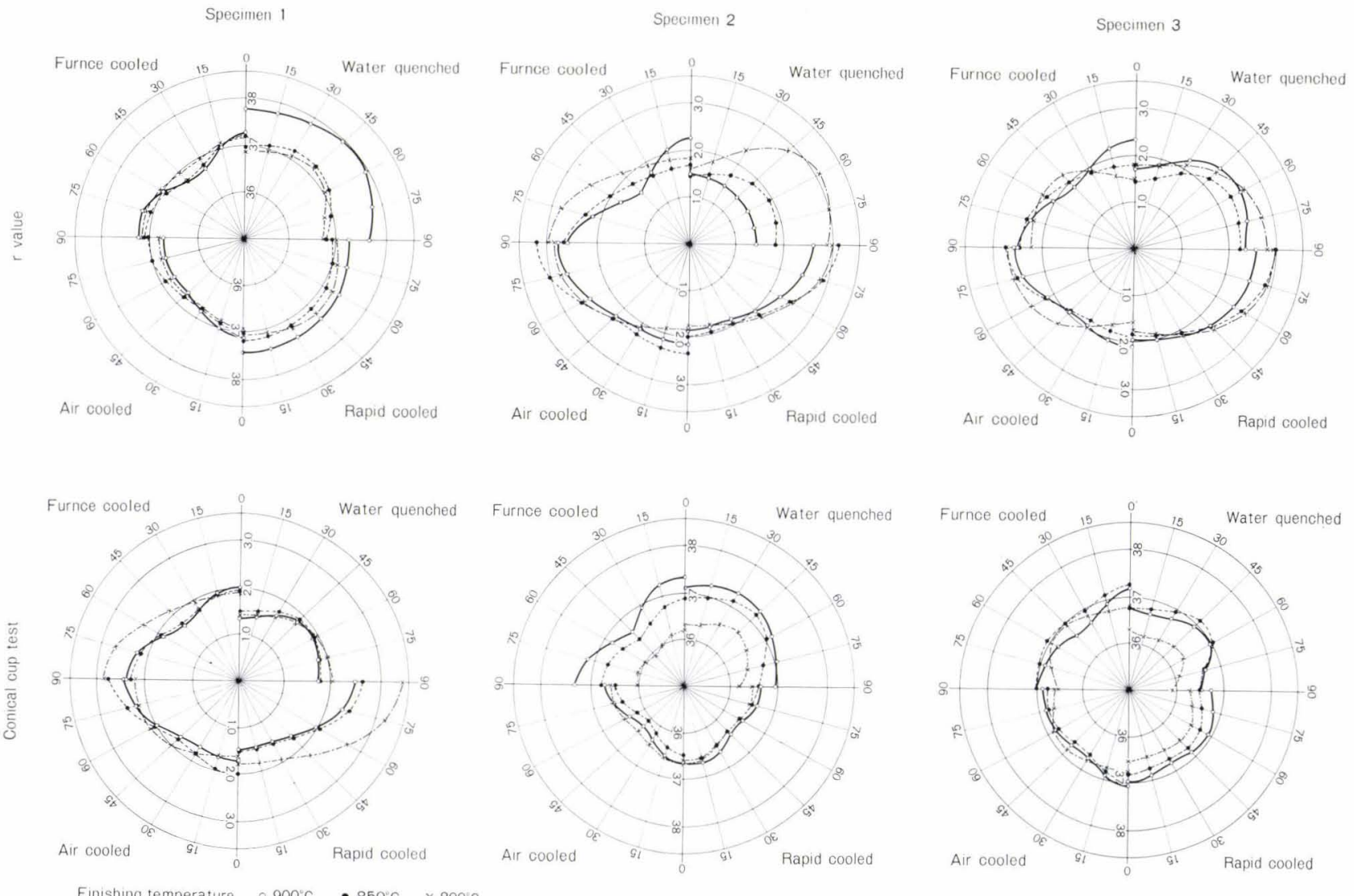

Fig. 1. Changes in $r$ value and flange shape of conical cup of cold-rolled and annealed sheets with the after hot-rolling cooling rates (Specimens were annealed at $780^{\circ} \mathrm{C}$ for $5 \mathrm{hr}$ ) 
3. Precipitation of $\mathrm{Nb}$ Carbonitride and X-ray Diffraction Intensity

In Fig. 2, the relation between the cooling rate after hot rolling and the quantity of $\mathrm{Nb}$ carbonitride as determined by the insoluble $\mathrm{Nb}$ (the residue when dissolved in $6 \mathrm{~N} \mathrm{HCl}$ ) is shown. The insoluble $\mathrm{Nb}$ of

Table 3. Changes in $\bar{r}$ value of cold-rolled and annealed sheets with the after hot-rolling cooling rates

\begin{tabular}{c|c|cccc}
\hline \multirow{2}{*}{ Specimen } & $\begin{array}{c}\text { Finishing } \\
\text { temper- } \\
\text { ature } \\
\left({ }^{\circ} \mathbf{C}\right)\end{array}$ & $\begin{array}{c}\text { Water } \\
\text { quenched }\end{array}$ & $\begin{array}{c}\text { Rapid } \\
\text { cooled }\end{array}$ & $\begin{array}{c}\text { Air } \\
\text { cooled }\end{array}$ & $\begin{array}{c}\text { Furnace } \\
\text { cooled }\end{array}$ \\
\hline \multirow{3}{*}{1} & 900 & 1.68 & 1.82 & 1.92 & 1.94 \\
& 850 & 1.75 & 1.89 & 2.08 & 1.93 \\
& 800 & 1.75 & 2.44 & 1.95 & 2.24 \\
\hline \multirow{3}{*}{2} & 900 & 1.45 & 2.14 & 2.36 & 1.96 \\
& 850 & 1.76 & 2.34 & 2.58 & 1.94 \\
& 800 & 2.58 & 2.29 & 2.35 & 2.36 \\
\hline \multirow{3}{*}{3} & 900 & 2.27 & 2.28 & 2.14 & 2.16 \\
& 850 & 2.01 & 2.37 & 2.11 & 2.09 \\
& 800 & 2.36 & 2.40 & 2.21 & 2.05
\end{tabular}

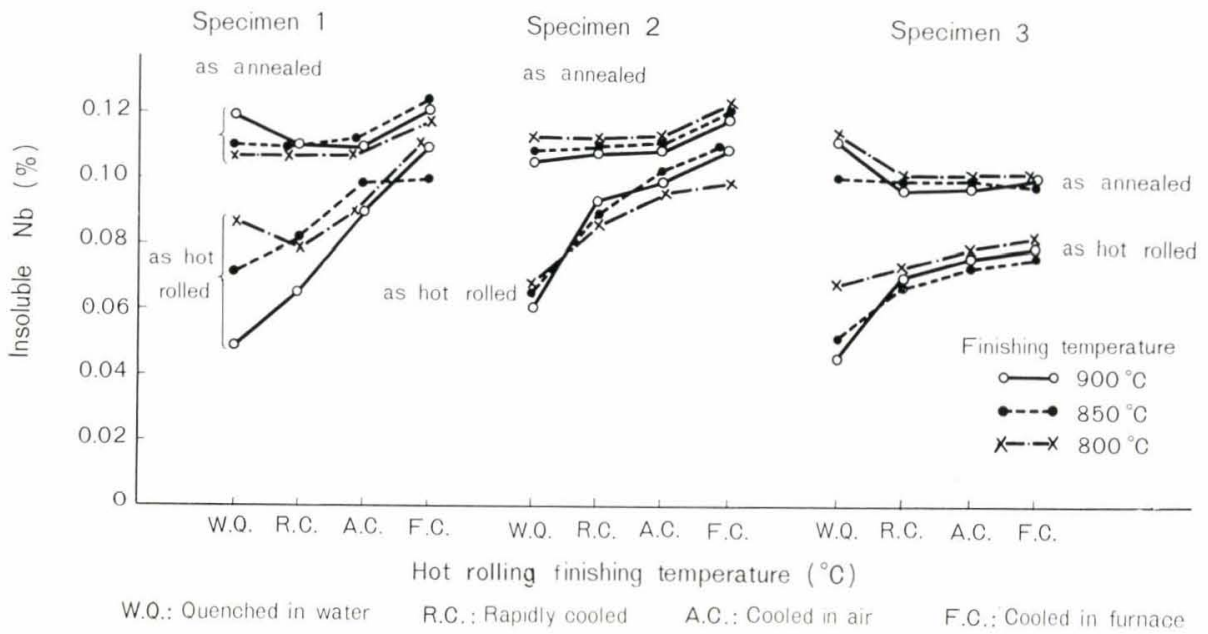

Fig. 2. Changes in insoluble $\mathrm{Nb}$ with the after hot-rolling cooling rates hot rolled sheets increases as the cooling rate decreases, and in the case of R.C. it decreases as the finishing temperature becomes lower. The insoluble $\mathrm{Nb}$ increases by the precipitation of $\mathrm{Nb}$ carbonitride during annealing, becoming almost constant irrespective of the hot rolling condition.

The X-ray diffraction intensities of the annealed sheets of Specimen 2 are shown in Fig. 3. The (222) intensities become maximum and (200) intensities minimum for A.C.

The size of $\mathrm{Nb}$ carbonitride as well as of grains of the hot rolled sheets change with the hot rolling condition. In Photo. 1, electron micrographs of $\mathrm{Nb}$

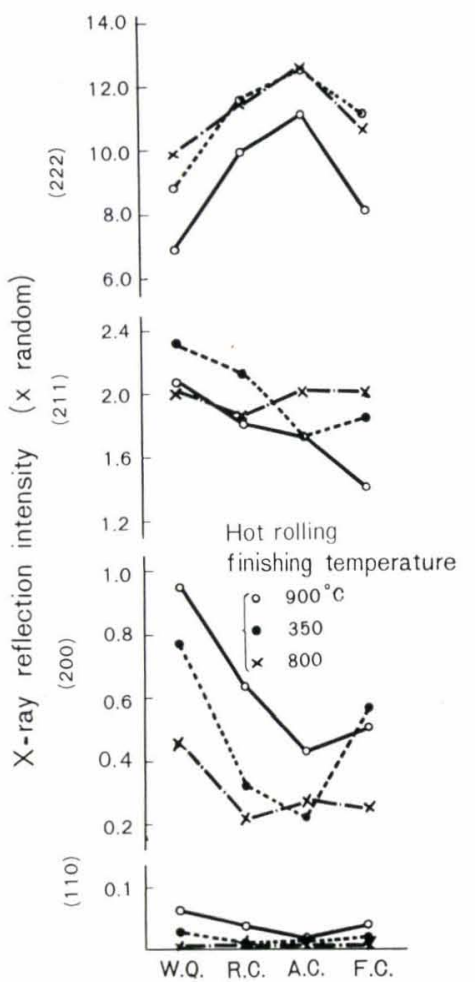

Fig. 3. Changes in X-ray diffraction intensities of cold-rolled and annealed sheets with the after hot-rolling cooling rates (Specimen 2)

\section{Type of cooling}

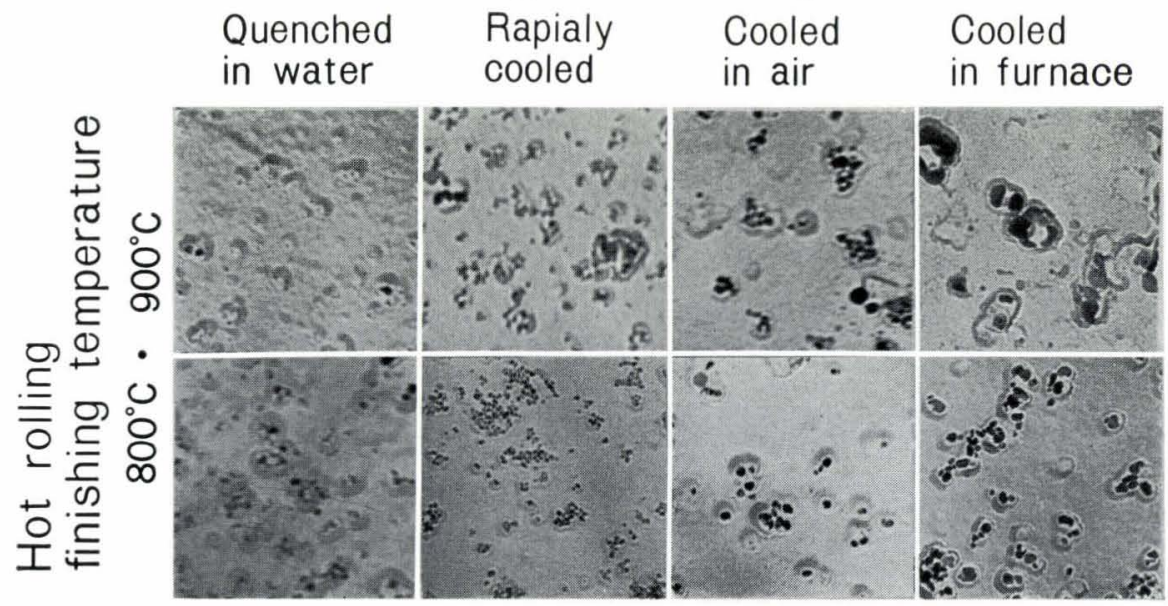

Photo. 1. Electron photomicrogaphs of $\mathrm{Nb}$ carbonitrides in hot-rolled sheets (Specimen 2, carbon extraction replica $)(\times 60000)(\times 5 / 6)$ 
carbonitride of Specimen 2 are shown for various hot rolling conditions. It will be seen that, although the particles are fine and uniformly distributed in W.Q. specimens, they get coagulated more as the cooling rate becomes slower and hot rolling finishing temperature higher. Thus, the size of particles appears to depend on the time in which the specimen is held through high temperatures.

Transmission electron micrographs of $\mathrm{Nb}$ carbonitride of annealed specimens are shown in Photo. 2. The shape of precipitates for the finishing temperature of $800^{\circ} \mathrm{C}$ is somewhat different from that for $850^{\circ} \mathrm{C}$ and above, where angular precipitates are found. This is especially clear with the W.Q. or F.C. specimens.

In Fig. 4, the recrystallization curves by hardness measurement are shown (heating rate $25^{\circ} \mathrm{C} / \mathrm{hr}$ ). Very little change is found among these curves for the same cooling rate, but some change is found in the recovery stage for specimens cooled differently from the same finishing temperature, especially for $900^{\circ}$ and $850^{\circ} \mathrm{C}$ : the recovery and softening proceeds more as the cooling rate becomes slower. This suggests that fine $\mathrm{Nb}$ carbonitrides in hot rolled sheets can coagulate and grow during annealing after cold rolling to influence the texture at recovery and recrystallization.

From those experiments, it was concluded that the planar anisotropy in $r$ value and flange shape of conical cup of annealed sheet change with the finishing temperature of hot rolling, presumably being affected by the quantity and distribution of $\mathrm{Nb}$ carbonitride precipitates.

\section{Change in Planar Anisotropy of Annealed Sheets with the Finishing Temperature of Hot Rolling and the Subsequent Cooling Time before Water Quench}

\section{Experimental Procedure}

To see the change of earing with the quantity and distribution of $\mathrm{Nb}$ carbonitride, Specimen 2 (Al-Si deoxidized) was hot rolled with the finishing temperatures of $900^{\circ}, 850^{\circ}$ and $800^{\circ} \mathrm{C}$, and left in air for several different periods of time before quenched in water. The sheets were cold rolled and annealed as before.

\section{Test Results}

The change in planar anisotropy in $r$ value as calculated by Hill's method and in flange shape of conical cup of annealed sheets are shown in Fig. 5. The earing upon conical cup test changes from diagonal to longitudinal-transverse as the time before water quench increases, but no clear correlations are found between planar anisotropy of $r$ value and flange shape of conical cup as before.

In Fig. 6, planar anisotropies of $r$ values, one as calculated by Hill's method and the other as measured actually, are shown with flange shape of conical cup (Specimen 3, hot rolled to $850^{\circ} \mathrm{C}$, water quenched immediately, cold rolled, annealed as

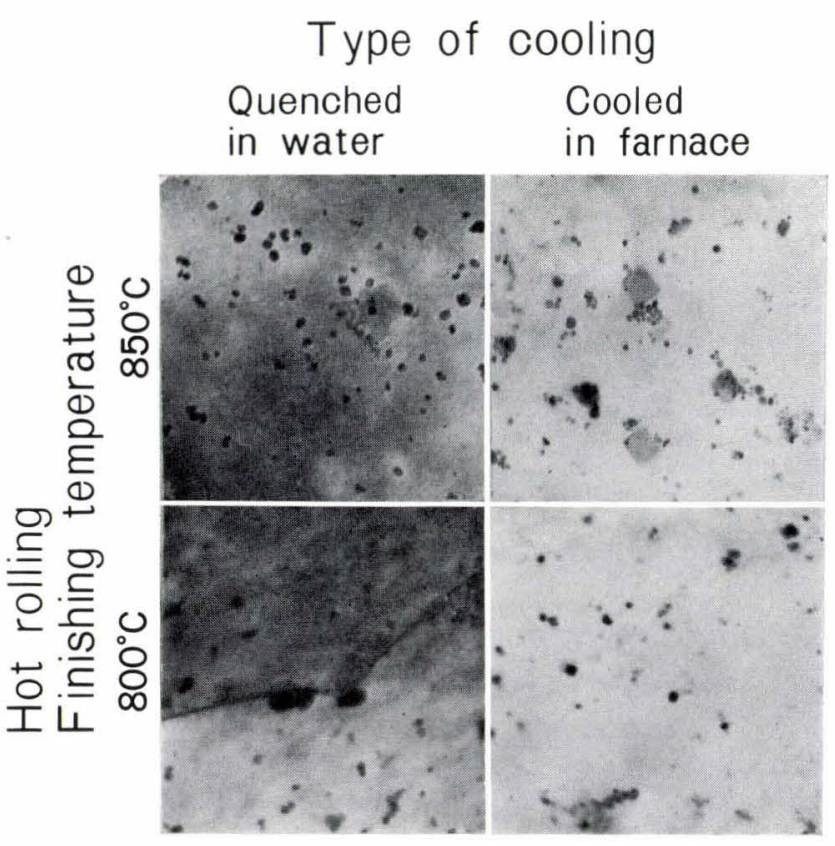

Photo. 2. Transmission electron photomicrographs of $\mathrm{Nb}$ carbonitrides in cold-rolled and annealed sheets (Specimen 2) $(\times 15000)(\times 4 / 5)$

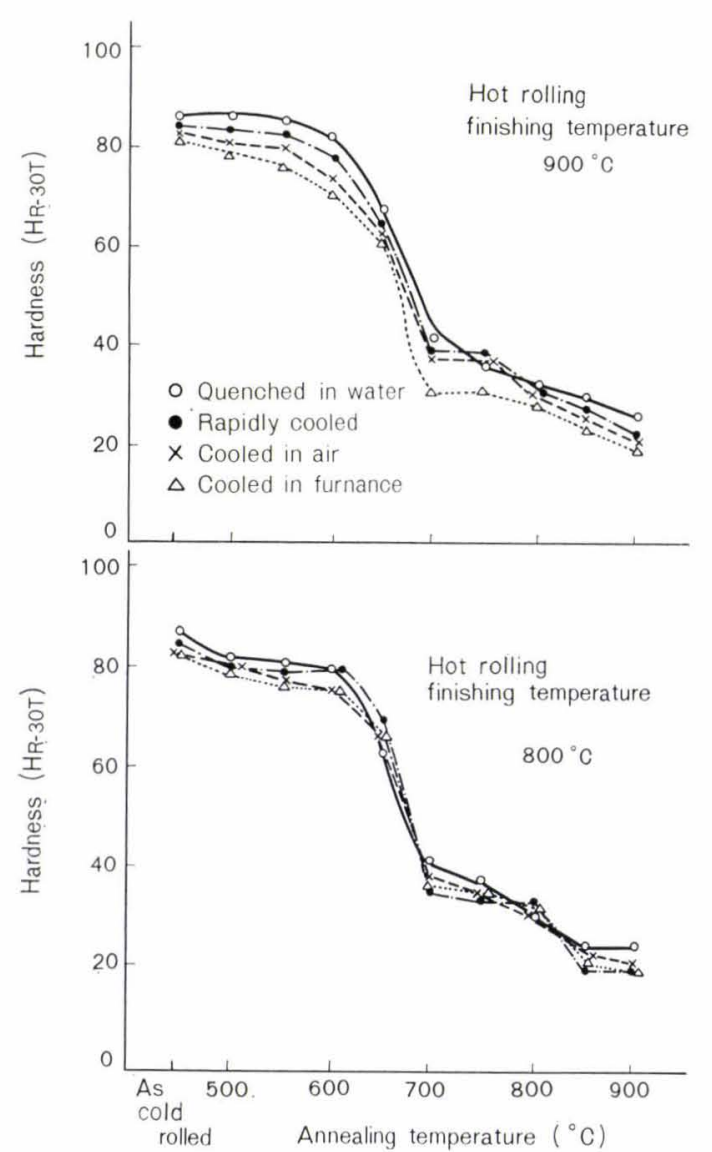

Fig. 4. Changes in recrystallization (hardness reduction) curves on annealing with finishing temperature and the after hot-rolling cooling rates (Heating rate, $25^{\circ} \mathrm{C} / \mathrm{hr}$ )

usual). It will be noted that there is a definite correlation between the flange shape and the planar anisotropy of $r$ value as measured but not with the calculated $r$ values. Therefore it is concluded that 


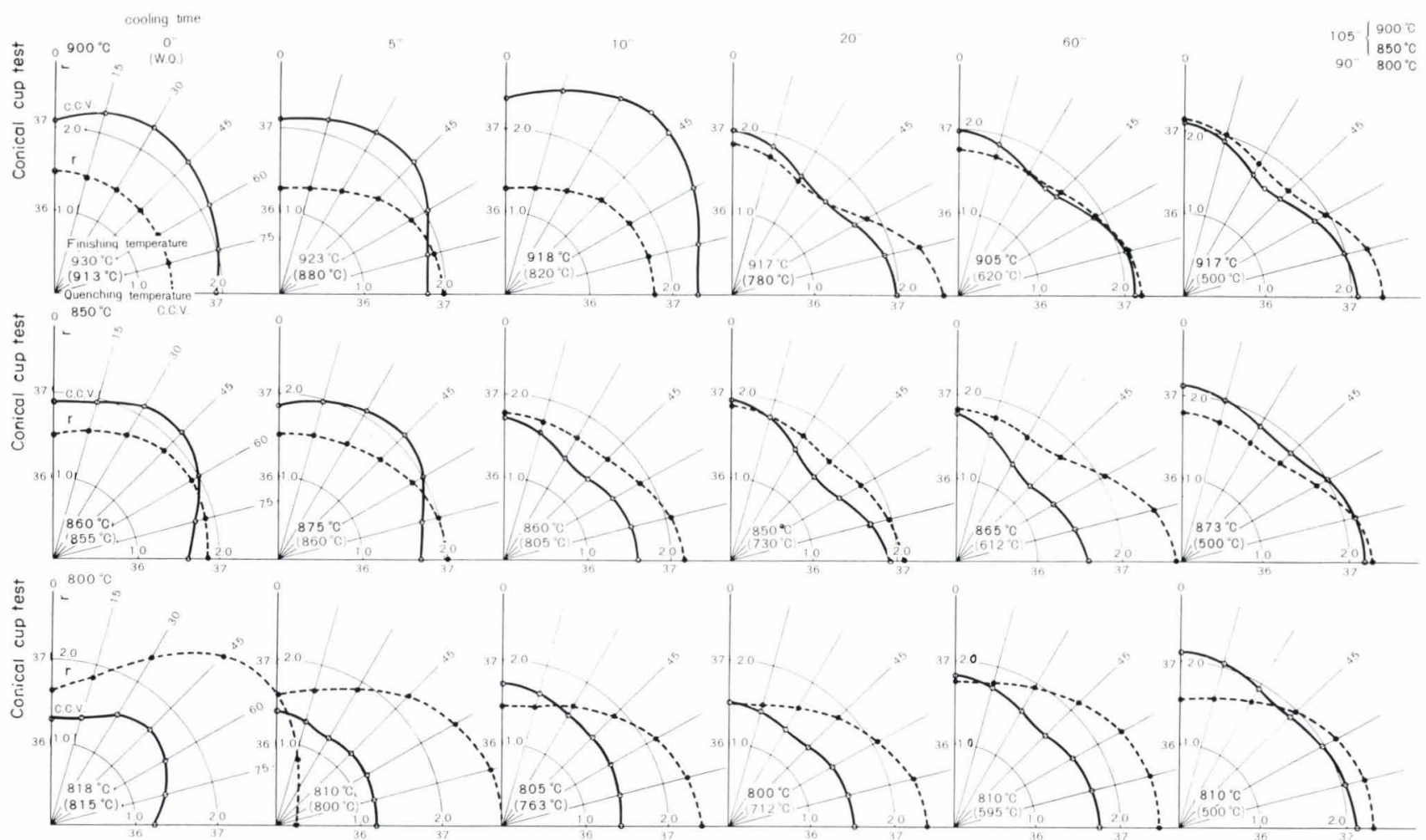

Fig. 5. Changes in flange shape of conical cup and $r$ value of cold-rolled and annealed sheets with the time of air cooling (sec) before water quench after hot rolling (Specimen 2)

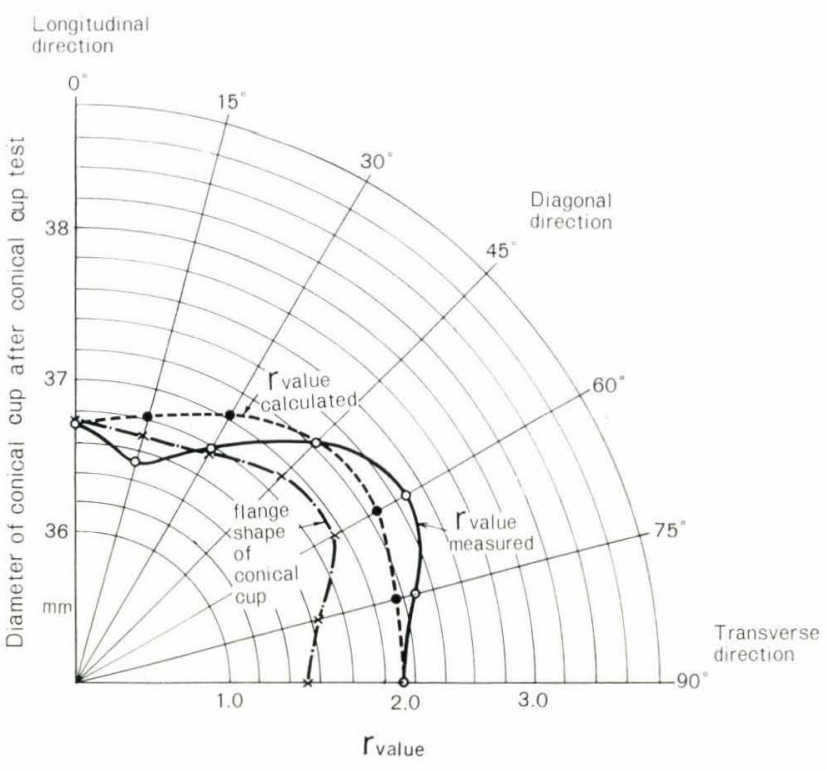

Fig. 6. Flange shape of conical cup and planar anisotropies of $r$ value (Specimen 3, hot rolling finishing temperature $900^{\circ} \mathrm{C}$, quenched in water, cold-rolled and annealed at $780^{\circ} \mathrm{C}$ for $5 \mathrm{hr}$ )

complex planar anisotropy of $r$ value like this case cannot be calculated by Hill's method. The earing changes from diagonal to longitudinal-transverse after 10,5 and 0 sec of air cooling time for the specimens finished at $900^{\circ}, 850^{\circ}$ and $800^{\circ} \mathrm{C}$, respectively.

In Fig. 7, the cooling curves after hot rolling are shown. There are horizontal parts near $800^{\circ}$ to $815^{\circ} \mathrm{C}$. The specimens that gave rise to diagonal earing were those that were quenched above this temperature, which was acertained to be the $\alpha-\gamma$

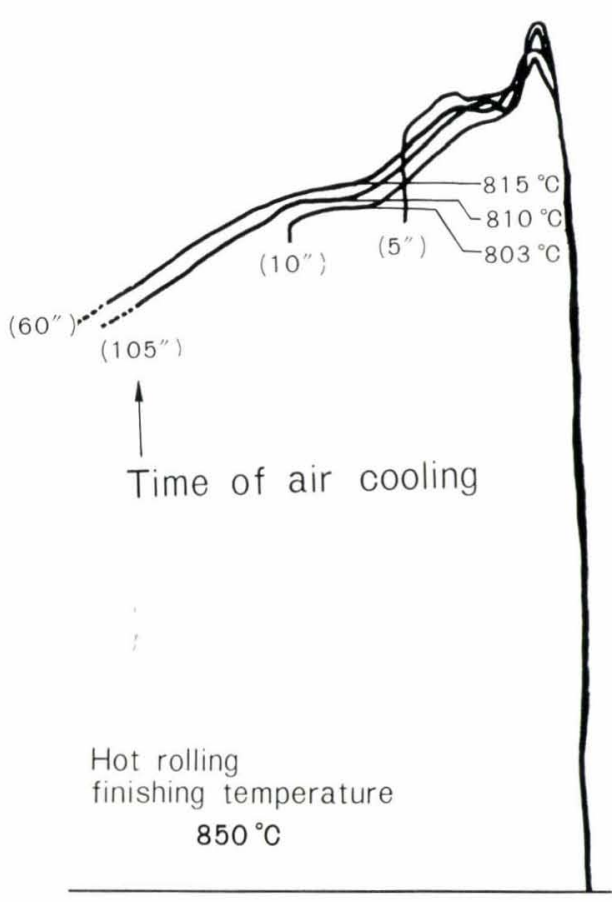

Fig. 7. Cooling curves after hot rolling (Specimens were hot-rolled, air cooled and water quenched.)

transformation point by dilatometry test using a $2.0 \mathrm{~mm} \phi$ specimen prepared from hot rolled sheet. It is concluded therefore that the planar anisotropy changes according to whether the transformation point is passed during the air cooling after hot rolling or not.

\section{Precipitation of $\mathrm{Nb}$ carbonitride}

In the experiment described above, it was made 


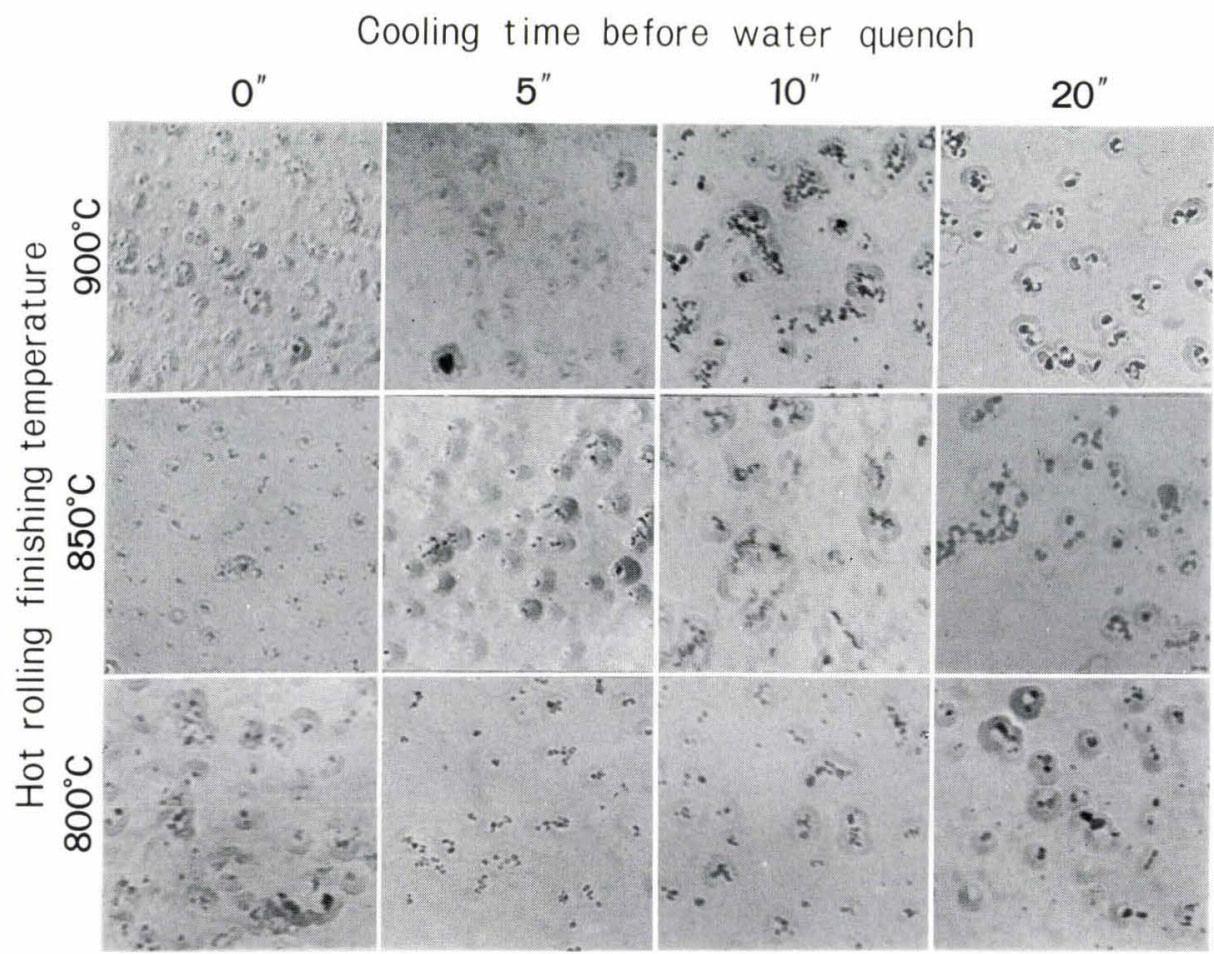

Photo. 3. Electron photomicrographs of $\mathrm{Nb}$ carbonitrides in hot-rolled sheets as quenched in water after air cooled for various periods of time (Specimen 2, carbon extraction replica) $(\times 60000)(\times 4 / 5)$

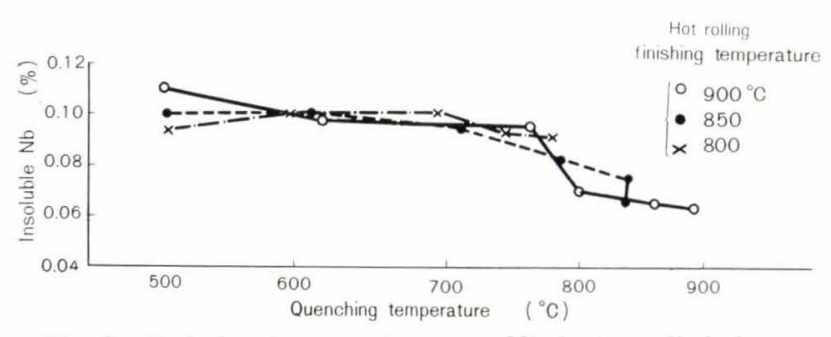

Fig. 8. Relation between insoluble $\mathrm{Nb}$ in hot-rolled sheets and quenching temperature after hot rolling

clear that the diagonal earing should be ascribed to $\mathrm{Nb}$ carbonitride precipitation occurring only in $\gamma$ state after hot rolling, whereas the longitudinaltransverse earing to precipitation in both $\gamma$ and $\alpha$. This has a close relation with the preliminary experiment: in the specimens cooled rapidly after hot rolling, precipitation proceeded mainly in $\gamma$ to become fine and uniformly distributed, whereas in slowly cooled ones, precipitation proceeded in a nearly equilibrium, the precipitates growing and coagulating.

The electron photomicrographs of Photo. 3 as well as the relationship between insoluble $\mathrm{Nb}$ in hot rolled sheets and quenching temperature after hot rolling, shown in Fig. 8, confirm the above conclusion.

\section{Change in Planar Anisotropy of Annealed Sheets with} Cooling Time before Water Quench after Hot Rolling

The change of planar anisotropy with differences in prior hot rolling may be ascribed to either of the following two reasons.

(1) On passing the $A_{3}$ transformation point during rolling, the texture of hot rolled sheet changes, and so does the texture of annelaed sheet.

(2) As the solubility products of $\mathrm{Nb}$ carbonitride in $\alpha$ is different from that in $\gamma$, the state of precipitation changes, causing the recrystallization texture to change.

In Fig. 9, the diffraction intensities as hot rolled, as cold rolled and as cold rolled and annealed are shown for the water quenching temperature after hot rolling. It will be seen that generally the intensities are all very weak, and no particular changes are found at around $800^{\circ} \mathrm{C}$. Further, as will be shown later, pole figures of hot rolled sheets do not show any fundamental change whether finished above the $\mathrm{A}_{3}$ point or below it.

With regard to the second factor, the distribution state of $\mathrm{Nb}$ carbonitride (the average numbers per unit area and the average particle diameter) was determined by the method of M. F. Ashby and R. Ebeling. ${ }^{17)}$ In Fig. 10, the average particle diameter and the average number per unit area of each specimen are shown for the finishing temperature. On passing the $\mathrm{A}_{3}$ transformation point, the average particle size increases while the average number decreases; this is because, as the solubility product of $\mathrm{Nb}$ carbonitride in $\alpha$ iron is much smaller than in $\gamma$ iron, some of the particles are allowed to grow at their previously precipitated sites.

In Fig. 11, changes of earing on conical cup test and in planar anisotropy with average particle size are shown. It will be seen in Fig. 11(a) that the diameter differential $[\mathrm{X}-\mathrm{L}]$ ( $\mathrm{X}$ and $\mathrm{L}$ being the diameters $(\mathrm{mm})$ of a conical cup measured in diagonal and longitudinal directions, respectively) decreases with the increase of average particle size, becoming zero at the size of ca. $140 \AA$. In Fig. 11(b), further, the relation of $\Delta r$ and average particle size is shown $\left(\Delta r=1 / 2 \times\left(r_{0}+r_{90}\right)-r_{45} ; r_{0}, r_{45}\right.$ and $r_{90}$ are the $r$ 


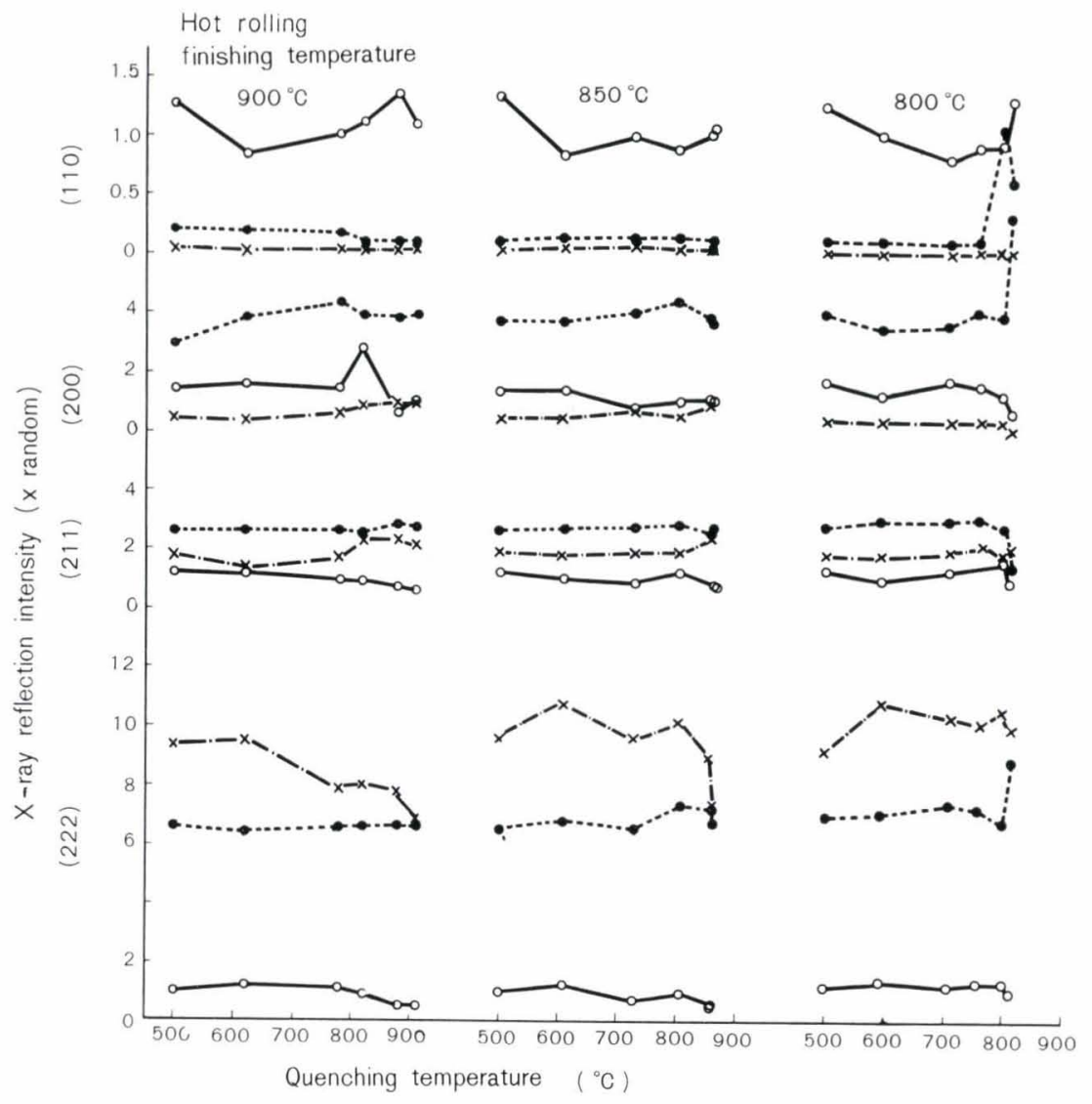

Fig. 9. Changes in X-ray diffraction intensities with quenching temperature after hot rolling (Specimen 2). The designated temperatures denote the finishing temperature, $\bigcirc$ as hot-rolled; $\bullet$ as cold-rolled; and $\times$ as cold-rolled.

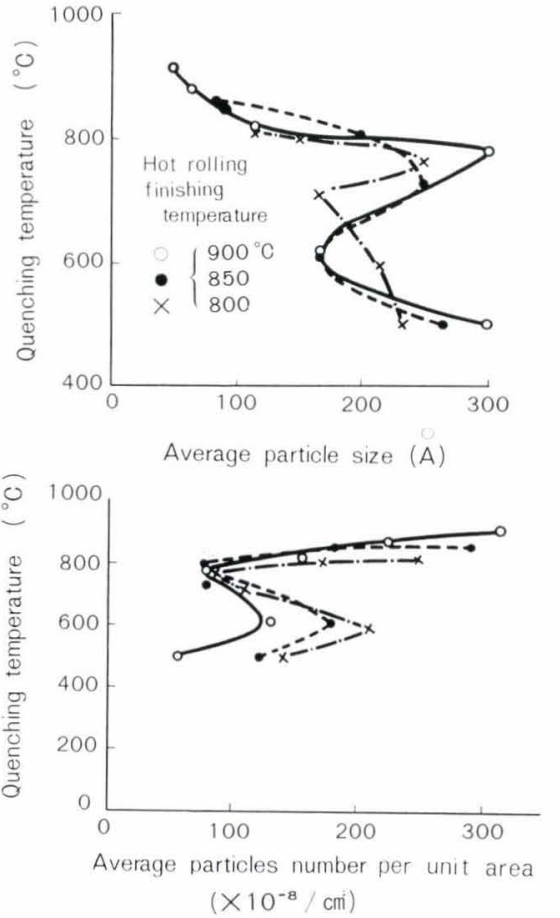

Fig. 10 .

Relations between average particle size and particle number per unit area in hot-rolled sheets and quenching temperature after hot rolling

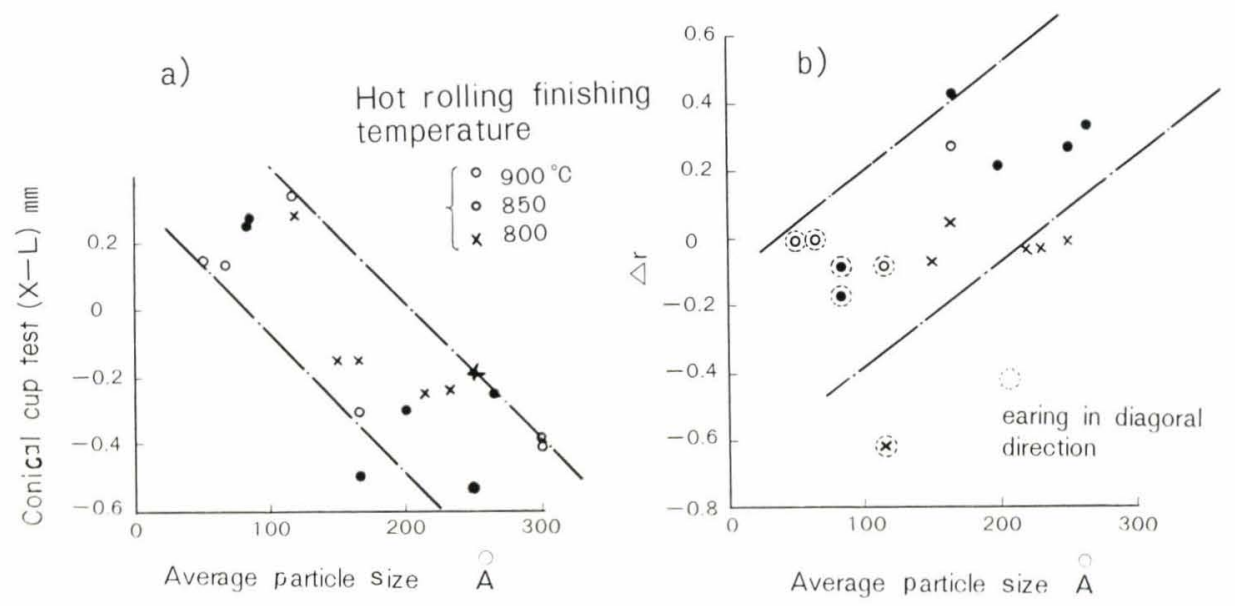

(a) Variation in the diametric anisotropy of a conical cup (X: the diagonal diameter $\mathrm{L}$ : the longitudinal diameter)

(b) Variation in the planar anisotropy $\left(\Delta r=1 / 2 \times\left(r_{0}+r_{90}\right)-r_{45}\right)$

Fig. 11. Relations between plastic anisotropies of cold-rolled and annealed sheets and average particle size in hot-rolled sheets

values of longitudinal, diagonal and transverse directions, respectively), where a similar tendency is to be observed. In Fig. 12, the relation between the diffraction intensities and average particle size is shown. There are maxima for (222) diffraction intensity and for the intensity ratio of (222) to (200), and a minimum for (200) diffraction intensity, all at an average particle size of 180 to $200 \AA$.

\section{Textures}

In Fig. 13, (200) pole figures of hot rolled, cold rolled, or annealed sheets of Specimens 2 and 3 are shown. Pole figures of series (a) are for the specimens quenched from the finishing temperature of nominally $800^{\circ} \mathrm{C}$, the cases which show maximum in the $\bar{r}$ value, whereas those of series (b) and (c) are for those of water quenched after $10 \mathrm{sec}$ and $20 \mathrm{sec}$ of air cooling, respectively, after hot rolling to a finish- 

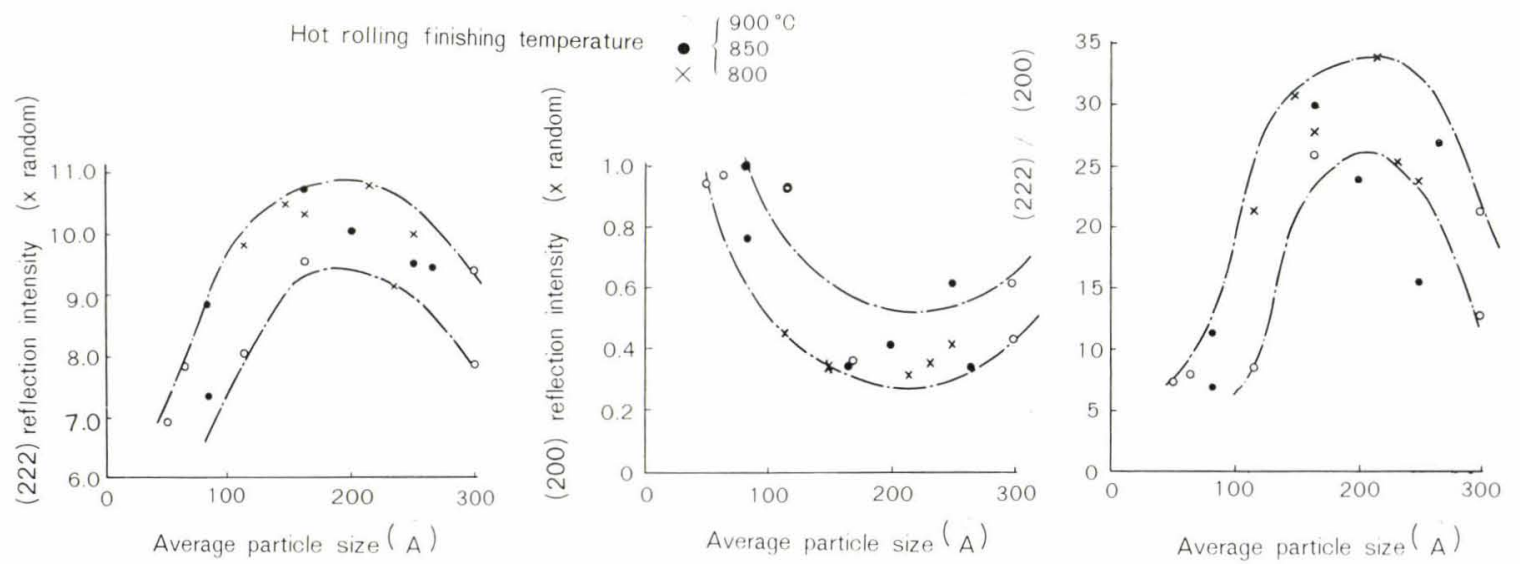

Fig. 12. Relations between X-ray diffraction intensity and average particle size

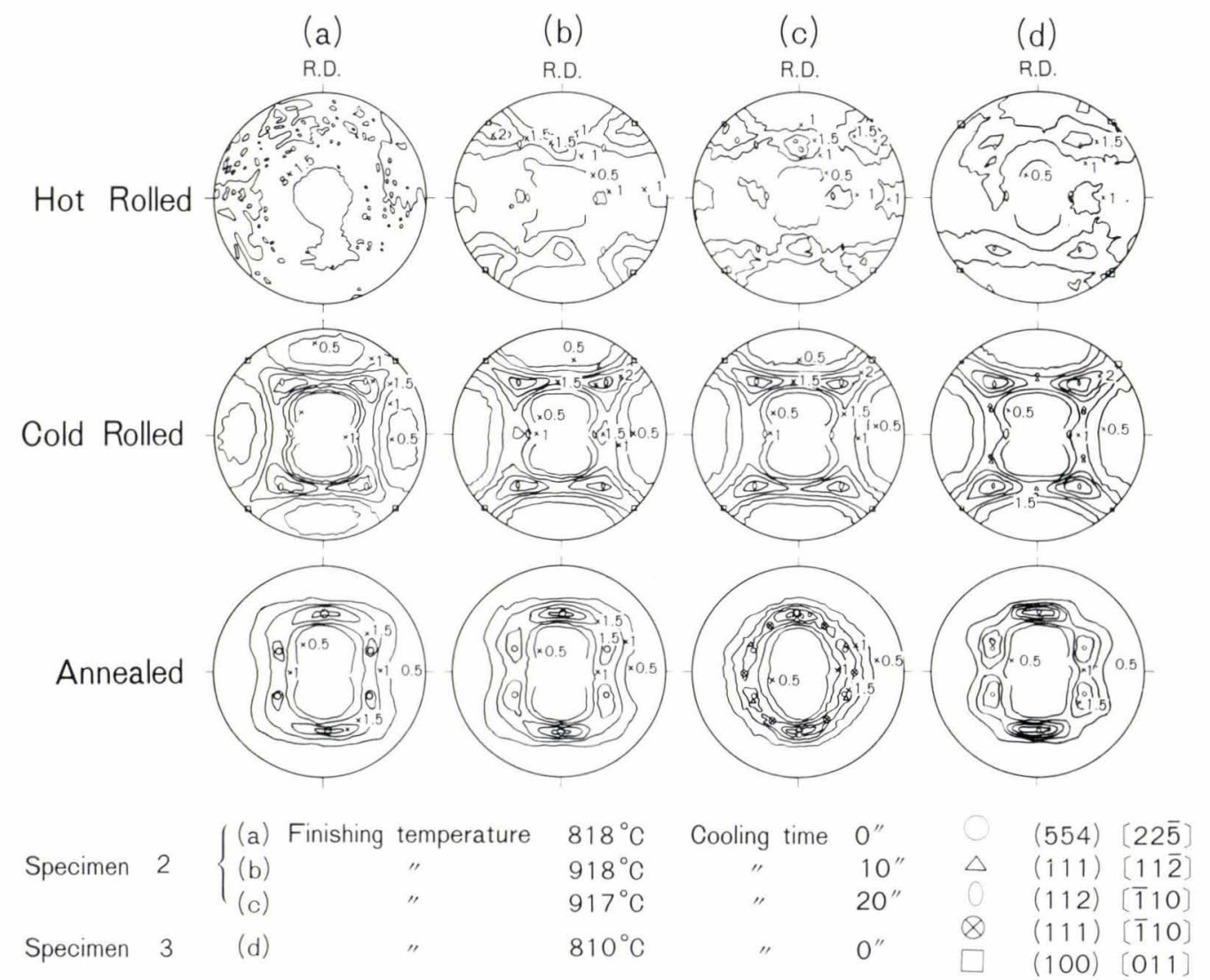

Fig. 13. Changes in (200) pole figures with the hot rolling conditions

ing temperature of nominally $800^{\circ} \mathrm{C}$. As previouly noticed, the change in direction of earing is found between (b) and (c).

It is clear from these figures that the textures of hot rolled sheets of specimens (b) and (c) are not much different, and no clear change occurs on passing the $\mathrm{A}_{3}$ transformation point. The same result was obtained about the cold rolling textures.

The recrystallization textures, however, show a remarkable change; that is, the main texture of (a) and (b) is (554) [225], whereas that of (c) is (111)

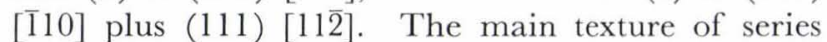
(d) specimen, which was deoxidized with $\mathrm{Si}$ and gave rise to 6 ears on conical cup test, is (554) [225] .

\section{Discussions}

The precipitation phenomena of $\mathrm{Nb}$ carbonitride are explained generally by the isothermal precipitation curves proposed by J. F. Grey and R. B. G. Yeo, ${ }^{18)}$ but when stress is imposed during the sheetmaking as in the case of hot rolling, the curves would suffer some alterations. Namely, as previously discussed, the fine and numerous particles of $\mathrm{Nb}$ carbonitride precipitated in $\gamma$ state coagulate and grow as the temperature decreases. But after passing the $\mathrm{A}_{3}$ transformation point, its nominal average particle size becomes smaller, and the number of particle increases as new fine precipitates make their appearances in $\alpha$. And as the temperature decreases further, they coagulate and grow again, untill finally a small number of large particles are remained. These phenomena are explained qualitatively in Photo. 3 and quantitatively in Fig. 10.

The explanation for the change of planar anisot- 
ropy of $r$ value with the difference of particle size discussed above is given for the change of particle size by cooling rates of the preliminary experiment.

In Fig. 14, (200) pole figures of an annealed specimen $(0.011 \% \mathrm{C}, 0.14 \% \mathrm{Nb})$ as quenched from either $\gamma$ or $\alpha$ state after hot rolling are shown. It will be seen that, when water quenched in $\gamma$, the main recrystallization texture is (554) [225] , whereas when quenched in $\alpha$, it is (111) [ 110$]$ plus (111) [11 $\overline{2}]$.

According to $\mathrm{H}$. Abe, ${ }^{19)}$ the formation of annealing

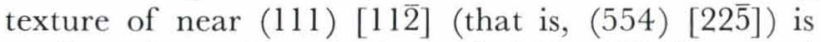
attributed to the rotation of (112) [110] around $\langle 110\rangle$ axis and that of (111) [110] is attributed to the rotation of (111) [112] around $\langle 111\rangle$ axis. In the present study, the annealing texture of specimen quenched in $\gamma$ after hot rolling appears to correspond to the former (near (111) [11 $\overline{2}]$ ), and that quenched in $\alpha$ to the latter ((111) [110]), though the details are to be studied further.

P. R. Mould and S. M. Gray ${ }^{14)}$ studied a low C steel containing $\mathrm{Nb}$ and reported that isothermal transformation at a high temperature, or in a simulated high temperature coiling followed by slow cooling, favors the development of higher $r$ value in the cold rolled and annealed sheets, and that the effectiveness of high (simulated) coiling temperatures in promoting high $r$ values is apparently related to the formation of $\mathrm{Nb}$ carbonitrides within the size range of 40 to $500 \AA$. I. F. Hughes and R. C. Hudd ${ }^{10}$ applied for a patent to obtain high $r$ values in cold rolled and annealed sheets of Nb-containing steels by such particular hot rolling practices or heat treatments that produce $\mathrm{Nb}$ carbides within a preferred size range of 80 to $500 \AA$. H. Abe and K. Takagi ${ }^{201}$ showed that the size and distribution of $\mathrm{Fe}_{3} \mathrm{C}$ particles in hot rolled sheet influence the annealing texture of an $0.06 \% \mathrm{C}$ rimmed steel: the hot rolled sheet solution-treated at $920^{\circ} \mathrm{C}$ for $1 \mathrm{hr}$ and water quenched developed a main texture of (554) [225] after cold rolling and annealing. This tendency was strong when the water quenched hot rolled sheet was tempered at $200^{\circ} \mathrm{C}$ for $3 \mathrm{hr}$. They believed that the $\mathrm{Fe}_{3} \mathrm{C}$ was dissolved when solution treated, reprecipitating after quenching and tempering as fine $\mathrm{Fe}_{3} \mathrm{C}$ precipitates to affect the annealing texture.

In the light of the present results and the previous report, it is suggested that different size and distribution of $\mathrm{Nb}$ carbonitride in hot rolled sheet has different effects on the texture (plastic anisotropy) of the annealed sheet, be it of $\mathrm{Nb}$ steel, of rimmed steel, or of steels containing $\mathrm{Ti}$ or other carbonitride forming elements.

On the other hand, though R. Gillanders and C. Dasarathy ${ }^{21}$ reported that soluble $\mathrm{Nb}$ affected hot rolling texture in that (112) [ [110] became sharper and responsible for the near (111) [11 $\overline{2}]$ of annealed texture, no such phenomenon was found in the present study as shown in Fig. 13.

\section{Summary and Conclusions}

(1) The $100 \mathrm{~kg}$ ingots ( $\mathrm{C} \sim 0.004 \%, \mathrm{Nb} \sim 0.12 \%$, deoxidized with $\mathrm{Al}, \mathrm{Al}-\mathrm{Si}$, or $\mathrm{Si}$ ) were forged and hot rolled to $3.2 \mathrm{~mm}$ with a finishing temperature of $900^{\circ}$, $850^{\circ}$ or $800^{\circ} \mathrm{C}$. After hot rolling they were cooled variously; water quenched, rapid cooled under water spray, cooled in air, or cooled in furnace. The hot rolled sheets were cold rolled to $0.8 \mathrm{~mm}$ and annealed at $780^{\circ} \mathrm{C}$ for $5 \mathrm{hr}$. The specimens quenched

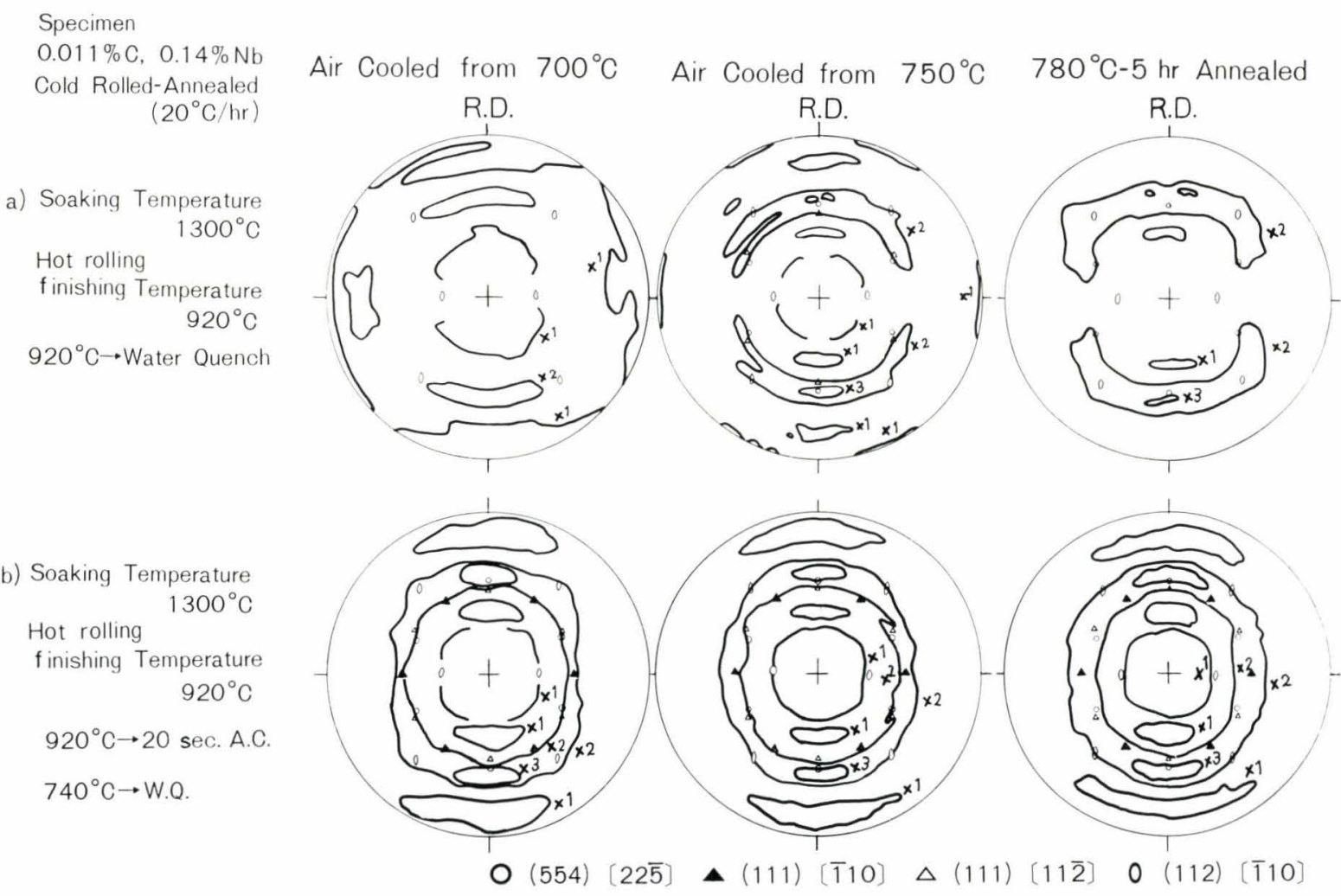

Fig. 14. Changes in (200) pole figures of cold-rolled and annealed sheets with hot rolling conditions 
after hot rolling showed earing in diagonal directions upon conical cup test. As the colling rates decreases, the earing showed the tendency to occur in longitudinal-transverse directions.

(2) The specimens that were water quenched from temperatures higher than about $810^{\circ} \mathrm{C}$ showed earing in diagonal directions, whereas those from temperatures lower than that showed earing in longitudinal-transverse directions. The border temperature was the $\mathrm{A}_{3}$ transformation point.

(3) Of the two possible reasons to account for the change of earing, i.e., (i) the change of hot rolling texture on passing the $\mathrm{A}_{3}$ transformation temperature, and (ii) the change of $\mathrm{Nb}$ carbonitride particle size due to the change of solubility products from $\gamma$ to $\alpha$, the (i) was denied as no fundamental change was found in the texture either as hot rolled or as cold rolled. It was found, however, for the cold rolled and annealed sheets, in those that showed earing in diagonal directions the main texture was (554) [225] , whereas in ones that showed earing in longitudinaltransverse directions it was (111) [1110] plus (111) [11 2$]$.

(4) On the other hand, however, electron microscopy study of hot rolled sheets revealed that there was an abrupt growth in the average particle size when the specimen was transformed from $\gamma$ to $\alpha$, and that when the average particle size was smaller than ca. $140 \AA$, the earing occurred in diagonal directions whereas when it was larger than $140 \AA$, the earing was in longitudinal-transverse direction.

(5) It was further found that the diffraction intensity ratio of (222) to (200) of the cold rolled and annealed sheet became the greatest when the particle size in the hot rolled sheet was 180 to $200 \AA$.

(6) Thus, it was concluded that the difference of earing can be explained by (ii), namely, by the dif- ference of $\mathrm{Nb}$ carbonitride particle size.

\section{REFERENCES}

1) F. M. Beeket and R. Franks: U.S. Patent 2, 264, 333, (1941), Dec. 2.

2) C. A. Edwards D. L. Phillips and H. N. Jones: JISI, 142 (1940), 199.

3) W. B. Morrison: JISI, 201 (1963), 317.

4) N. Fukuda: Tetsu-to-Hagané, 59 (1973), 231.

5) N. Fukuda and M. Shimizu: Journal of Japan Society for Technology of Plasticity, 13 (1972), 841.

6) D. A. Karlyn, R. W. Vieth and J. L. Foland: Mechanical Working and Steel Processing, VII, AIME, New York, (1969), 127.

7) R. H. Goodenow and J. F. Held: Met. Trans., 1 (1970), 2507.

8) T. Matsuoka and M. Takahashi: Tetsu-to-Hagané, 57 (1971), 1134.

9) F. Terasaki and T. Kaneko: Tetsu-to-Hagané, 58 (1972), 1674 .

10) I. F. Hughes and R. C. Hudd: British Patent Specification 1236598, published June 23, 1971.

11) Armco Steel Corp.: Japan laid-open Specification, S-462658, (1971).

12) O. Akisue and K. Takashina: J. JIM, 36 (1972), 1124.

13) R. E. Hook and J. A. Ellias: Met. Trans., 3 (1972), 2171.

14) P. R. Mould and S. M. Gray: Met. Trans., 3 (1972), 3121.

15) I. Kokubo, M. Sudō, K. Kameno, S. Hashimoto, I. Tsukatani and T. Iwai: Tetsu-to-Hagané, 59 (1973), 469.

16) R. Hill: The Mathematical Theory of Plasticity, Oxford Press, (1950), 323.

17) M. F. Ashby and R. Ebeling: Trans. AIME, 236 (1966), 1396.

18) J. M. Gray and R. B. G. Yeo: Trans. ASM, 61 (1968), 255.

19) H. Abe: Tetsu-to-Hagané, 52 (1966), 882.

20) H. Abe and K. Takagi: Tetsu-to-Hagané, 55 (1969), 1219.

21) R. Gillanders and C. Dasarathy: British Steel Corp, Open Report SM/690/A, (1973). 